\title{
Finite element method for the rising and the slip of column-plate base for usual connections
}

\author{
M. Hamizi ${ }^{1,1}$, H. Ait aider ${ }^{1}$, A. Alliche ${ }^{2}$, and N.E. Hannachi ${ }^{1}$ \\ ${ }^{1}$ Département de Génie civil, Université Mouloud Mammeri, BP 171500 Tizi-Ouzou, Algérie \\ ${ }^{2}$ Institut Jean le Rond d'Alembert, Université Pierre et Marie Curie, 75252 Paris Cedex, France
}

\begin{abstract}
In the present paper, a finite element approach calculating the rising and the relative slip of steel base plate connections is proposed. Two types of connections are studied, the first consists on a base plate welded to the column end and attached to the reinforced concrete foundation by two anchor bolts. These bolts are placed on the major axis of the I shaped section used as column, one anchor bolt on each side of the web. In the second configuration, the connection includes a plate base and four anchor bolts placed out side the flanges of the I shaped section or hallow form. To take in account the real behaviour of this connection, a model by finite elements which considers count geometrical and material no linearties of the contact and cracking in the concrete foundation. To study the rising of the base plate, an approach treating problems of contact-friction between the base plate and the foundation is developed. This approach is based on a unilateral contact law in which a Coulomb friction is added. The numerical resolution is ensured by the increased Lagrangien method. For the behaviour of the concrete foundation, the developed model is based of a compressive elastoplastic model. The heights rising-rotations and the heights rising- slip displacements curves are plotted.
\end{abstract}

\section{Introduction}

The base plate is necessary to transmit to the reinforced concrete foundation the effort acting in the column. The dimensions of the base plate $(b \times d)$ are given by considering the pressure transmitted to the subjacent concrete, witch must resist without rupture. The thickness of the base plate $\left(t_{p}\right)$ is given by considering the pressure transmitted by the concrete. The number of anchor bolts, the space between the bolts just as the welding connecting the column to the base plate are other factors which can influence the choice of dimensions of the base plate. The dimensioning of the base plate is a relatively simple work is one has tables and abacuses of calculation like those proposed by Stockwell [1], Sandhu [2], Bird [3], C.M. 66 [4], Euro code [5]. The recent studies as well experimental as numerical showed all that other parameters could influence the behaviour of the base plate like rising and the slip. The rising and slip are generated by the contact between the base and the reinforced concrete foundation. During the last decades, a significant work dealing with the problem of rising and slip between base plate and reinforced concrete foundation were carried out by many researches. Several approaches were used: experimental approach, analytical approach and the numerical development. The tests at the laboratory showed all that the separation of the connection is always made on the level surface of contact between the base plate and reinforced concrete foundation which is assumed as fully rigid connection [6-8]. Other experimental investigation under concentrated loads and offset loads describing and evaluating the response of the column base connections were carried out [9-12]. The analytical approach, on the other hand, based on a variable distribution of the reaction of the reinforced concrete foundation on the base plate under a weak concentrated load applied in the top of the column gave a significant surface of contact [13-14]. Another approach, by finite elements method, to evaluate the rising and the slip of the base plate compared to the reinforced concrete foundation was realized these last years [15-16]. Several models were used. The model with one dimension based on the theory of Bernoulli where the anchor bolt is modelled as a spring gave results at

\footnotetext{
${ }^{1}$ e-mail : chamizi@yahoo.fr
}

This is an Open Access article distributed under the terms of the Creative Commons Attribution-Noncommercial License 3.0, which permits unrestricted use, distribution, and reproduction in any noncommercial medium, provided the original work is properly cited. 
least mitigated [17]. On the other hand, models with two (2D) and three dimensions (3D), which have the following advantages:

- Visualization of normal and tangential displacement

- Precise numerical results

- Minima costs of data processing

- showed all the rising and the slip between the base plate and the reinforced concrete foundation [18-25].

\section{Development of the model by finite element}

Taking into account studies enumerated above and the various recommendations made by the authors, we built a three-dimension finite element model based on the non linear analysis of the structure to simulate the behaviour of column base plate connection. The model takes into account the non linearity of materials and the non linearity of contact between the foundation and the base plate, where it simulates the rising and the slip of the base plate and where friction at the interface concrete foundation - base plate is ensured by four nodes quadratic elements [26]. The model is established in code computer CASTEM3M. The aim of this study is the analysis of the behaviour of the column-base plate connections most usually used. For this purpose, the curves of rising according to rotations and the normal displacement according to the tangential displacement are plotted.

\section{Unilateral contact (or Signorini)}

In numerous simulations, the law of unilateral contact used is illustrated by the problem of Signorini. Let us consider a deformable body in contact with a rigid body (fig.1.), the conditions of unilateral contact of Signorini having to be respected in all points of the deformable bodies located on the contact $\Gamma_{C}$ is [27]:

$$
\begin{aligned}
& h \leq 0 \\
& R_{\vec{n}} \leq 0 \\
& h \cdot R_{\vec{n}}=0
\end{aligned}
$$

with $\mathrm{h}$ the interstice or the displacement of a point of contact in the normal direction to the contact $\vec{n}$ and $R_{\vec{n}}$ the components of the normal effort. The equation (1) translated the condition of impenetrability; the equation (2) the fact that the normal force of contact is compression and the equation (3) represents the condition of complementarily (if the point is in contact then $h=0$ and $R_{\vec{n}} \leq 0$ if the point leaves the contact then $h \prec 0$ and $\left.R_{\vec{n}}=0\right)$ ) [27].

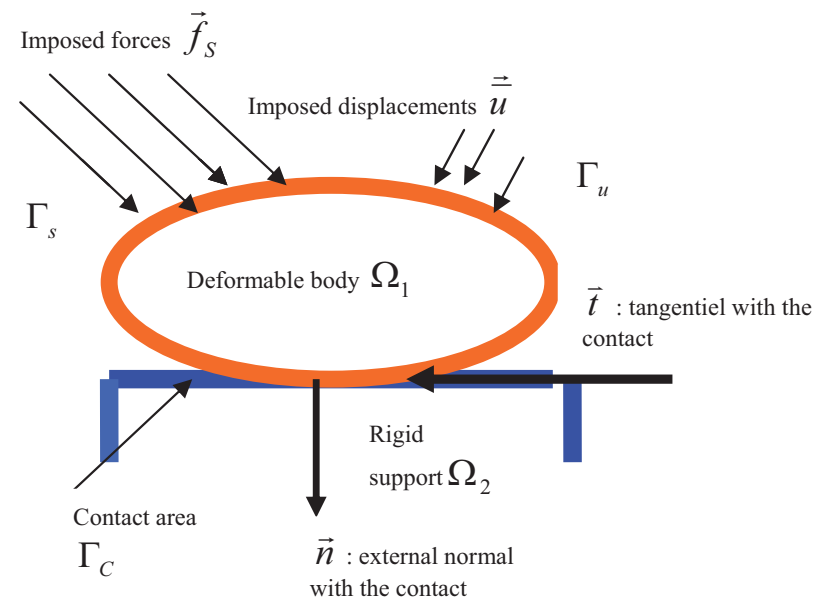

Fig.1. Contact between a deformable body and rigid body (Signorini problem) 


\section{Coulomb law}

The force at the point of contact can break up into a normal force $R_{\vec{n}}$ and a tangential force $R_{\vec{t}}\left(\vec{R}=R_{\vec{n}} \cdot \vec{n}+R_{\vec{t}} \cdot \vec{t}\right)$. The model of Coulomb is written in the following way [27]:

$$
\begin{aligned}
& \left|R_{\vec{t}}\right| \leq \mu \cdot\left|R_{\vec{n}}\right| \\
& \left|R_{\vec{t}}\right| \prec \mu \cdot\left|R_{\vec{n}}\right| \Rightarrow v_{\vec{t}}=0 \quad \text { (adherence) } \\
& R_{\vec{t}}=-\mu \cdot\left|R_{\vec{n}}\right| \cdot \frac{v_{\vec{t}}}{\left|v_{\vec{t}}\right|} \quad \text { (slip) }
\end{aligned}
$$

with $v_{\bar{t}}$ tangential relative speed between the two bodies and $\mu$ the friction coefficient of Coulomb (Fig.2.) which includes all the local parameters, such as roughness between the two bodies.

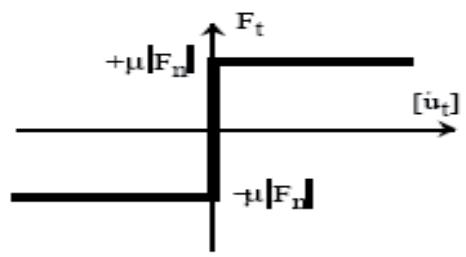

Fig.2. Coulomb law

\section{Equilibrium without friction}

The deformable body is considered $\Omega_{1}$ and the rigid body $\Omega_{2}$, we note $\Omega=\Omega_{1} \cup \Omega_{2}$ the whole of the bodies. The deformable body is subjected to the imposed displacements $\vec{u}_{d}$ on the zone $\Gamma_{u}$, to imposed efforts $\vec{f}_{s}$ on the zone $\Gamma_{\sigma}$, and to forces of volumes $\vec{f}_{v}$ acting on the field (Fig.1.)

$$
\begin{array}{lc}
\operatorname{div} \vec{\sigma}+\vec{f}_{v}=0 & \text { in } \Omega \\
\vec{u}=\vec{u}_{d} & \text { on } \Gamma_{u} \\
{[\sigma] \cdot \vec{n}=\vec{f}_{S}} & \text { on } \Gamma_{\sigma} \\
{[\sigma] \cdot \vec{n}=\vec{R}} & \text { on } \Gamma_{C}
\end{array}
$$

Equilibrium of deformable body $\Omega_{1}$ with frictional contact is written:

$$
W_{\text {solide }}=\frac{1}{2} \int_{V}[\sigma]:\{\varepsilon\} d V-\int_{V} \vec{f}_{V} \vec{u} d V-\int_{C_{C}} \vec{f}_{S} \cdot \vec{u} d S-W_{\text {cont }}
$$

The work of the actions of contact on the deformable body is written:

$$
\begin{aligned}
& W_{\text {cont }}=\iint_{\Gamma_{C}}\left(R_{n} \vec{n} \cdot \vec{u}_{n}+\vec{R}_{t} \cdot \vec{u}_{t}\right) d S \\
& \text { with } \vec{u}_{t}=\left(\vec{u}_{2}-\vec{u}_{1}\right)-\vec{u}_{n} \cdot \vec{n}
\end{aligned}
$$

The actions of rigid body $\Omega_{2}$ on body $\Omega_{1}$ are written:

$$
\vec{f}_{\text {cont }}=\iint_{\Gamma_{C}}\left(R_{n} \cdot \vec{n}+\vec{R}_{t}\right) d S
$$




\section{Finite element modelling}

$\begin{array}{ll}\sigma=C: \varepsilon & \text { Behaviour law } \\ \varepsilon=[B] \cdot u & \text { Interpolation of deformations } \\ u=[N] \cdot u^{k} & \text { Interpolation of displacements }\end{array}$

In matrix form the equation (11) is written

$$
W_{\text {solide }}=\left(\frac{1}{2} u^{T}[K] \cdot u-u^{T}\{F\}\right)
$$

with $[K]=\int_{V} B^{T}[C] B d V \quad$ rigidity matrix

$$
\text { and }\{F\}=\int_{V}\left[N^{T}\right] \vec{f}_{V} d V+\int_{\Gamma_{C}}\left[N^{T}\right] \vec{f}_{S} d S+\int_{\Gamma_{C}}\left[N^{T}\right] \vec{f}_{\text {cont }} d S\{F\} \quad \text { vector of the external efforts }
$$

The equilibrium of system with frictional contact amounts to minimize the energy equation under the following constraint:

$$
\left\{\begin{array}{c}
\operatorname{div} \sigma \equiv \delta W_{\text {solide }}=0 \\
h=\left(\left(\vec{u}_{2}-\vec{u}_{1}\right) \cdot \vec{n}\right) \cdot \vec{n}=[G]^{T} u_{n}=0
\end{array}\right.
$$

\section{Method of resolution (increased Lagrangien)}

$$
\begin{gathered}
W_{\text {solide }}(u, \lambda)=\frac{1}{2} u^{T}[K] u+\lambda^{T}[G]^{T} u+\frac{\alpha}{2} u^{T}[G][G]^{T} u=0 \\
\delta W_{\text {solide }}(u, \lambda)=0 \Rightarrow\left\{\begin{array} { c } 
{ \frac { \partial W } { \partial u } = 0 } \\
{ \frac { \partial W } { \partial \lambda } = 0 }
\end{array} \Rightarrow \left\{\begin{array}{c}
{\left[K+\alpha G G^{T}\right] u^{K}+[G] \lambda^{K}=F} \\
\lambda^{K+1}=\lambda^{K}+\alpha[G]^{T} u^{K}
\end{array}\right.\right.
\end{gathered}
$$

\section{Numerical analysis}

Three types of connections are studied, the first one consisting of a base plate $\left(t_{p}=11 \mathrm{~mm}\right)$ welded to the end of column and attached to the reinforced concrete foundation with two anchor bolts. These bolts are placed on the major axis of the I shaped column cross- section, one anchor bolt on each side of the web (Fig.5.) In the second configuration, the connection comprises a base plate $\left(t_{p}=30 \mathrm{~mm}\right)$ and four anchor bolts placed outside the flanges of the $\mathbf{I}$ shaped section (Fig.6.). In the third configuration, the connection comprises a base plate $\left(t_{p}=19 \mathrm{~mm}\right)$, a column with a hollow cross-section and four anchor bolts (Fig.7). Two loading types are used. First, the connections were subjected to shear force and a bending moment only, and then the connections were put under shear force, a bending moment and an axial compressive force (Fig.8). In this case a bending moment is caused by the offset compressive load. Different eccentricities and variable axial loadings $(\mathrm{P}=100$ to $600 \mathrm{KN}$ ) are chosen, in order to show the influence of these parameters of the degree of fixity of the column base connections. In this study, the following assumptions were assumed in order to obtain essential response features:

- An interaction between the holes being in the base plate and the anchor bolts is ensured by considering a unilateral contact between these two bodies

- In order to simplify the mesh, the anchor bolts that are of circular sections are simulated in this study by bolts of square sections of equivalent surface.

- The discrimination of the anchor bolts is made so that the nodes coincide with the nodes of the holes of the base plate. 
- To take into account the problem of contact friction between the base plate and the foundation, the nodes as well as the degrees of freedom of the two bodies are selected so that they coincide

- The same precaution is also taken with regard to the nodes and the degrees of freedom of the anchor bolts and the concrete foundation

- Traction in the concrete develops only in the high part of bolt (on the third of $\mathrm{L}_{\mathrm{P}}$ )

- The loadings are introduced in the forms of increments (ensured well by CASTEM3M code)

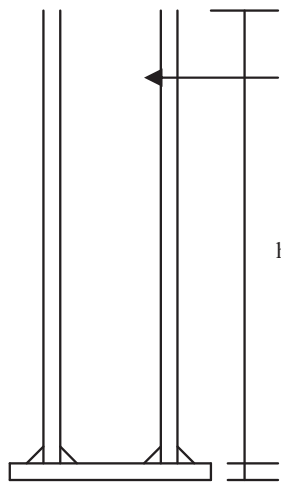

\section{HEB 100}

70

30
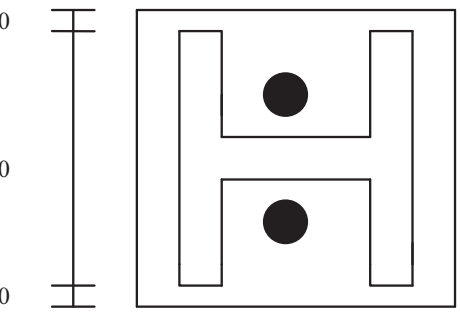

$t_{p}=11 \mathrm{~mm}$

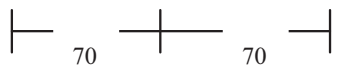

Fig.3. Detail of two anchors bolts connection
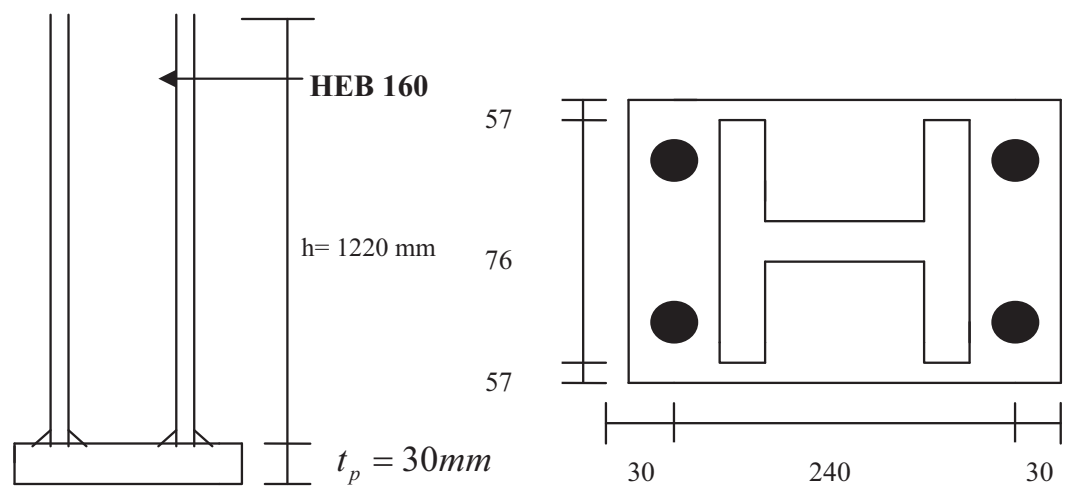

Fig.4. Detail of four anchors bolts connection
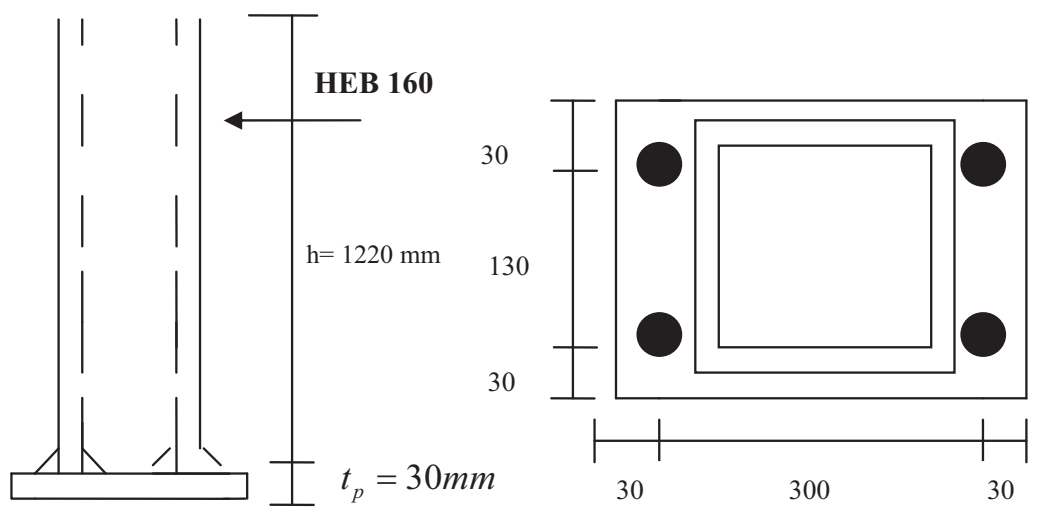

Fig.5. Detail of four anchors bolts connection with a hollow cross-section 


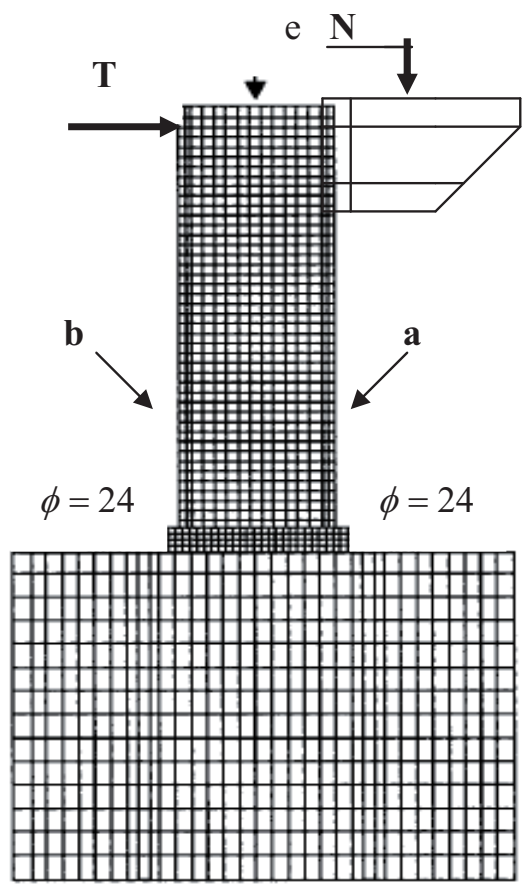

Fig.6. Finite element mesh of the 3-D model

\section{Results}
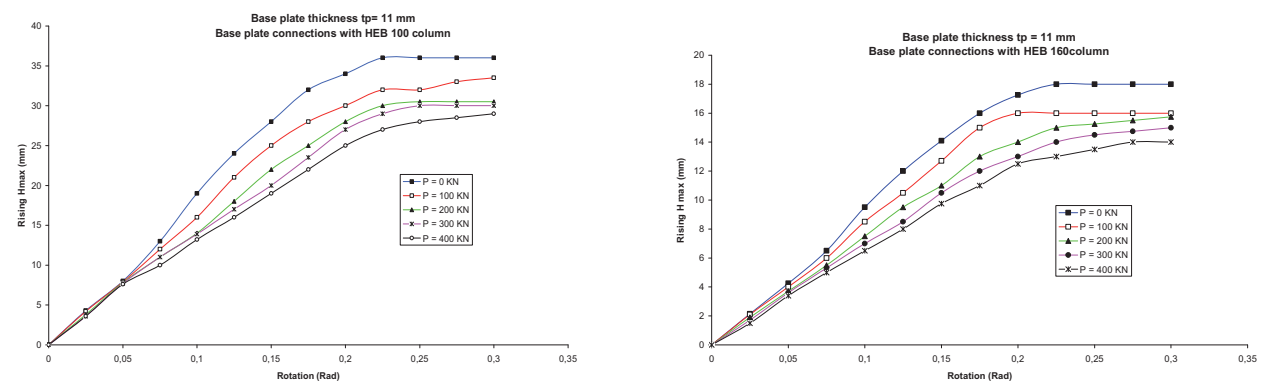

Fig. 7. Maximum rising-rotation diagrams for base plate thickness tp $=11 \mathrm{~mm}$ under various axial loadings.Base-plate connections with HEB 100 and HEB 160column.
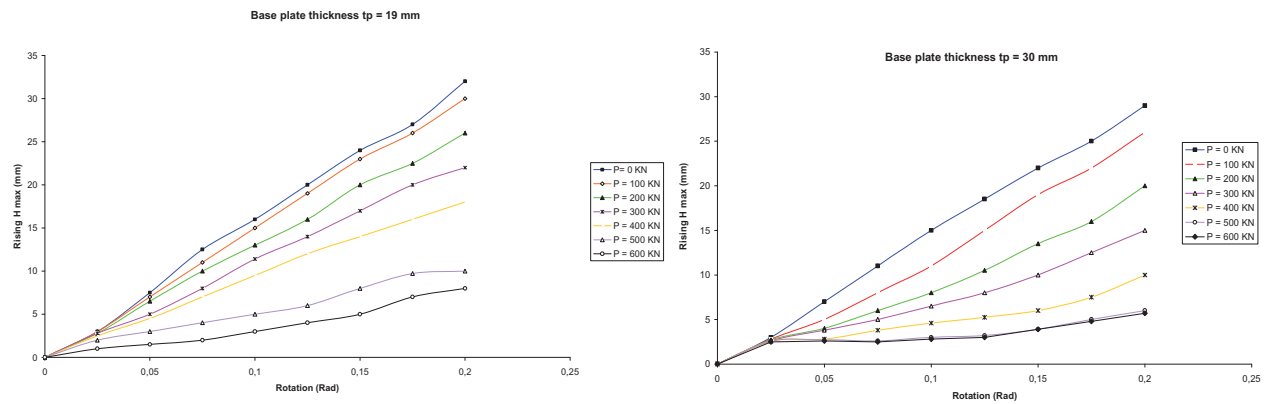

Fig.8. Curves of the rising of the $19 \mathrm{~mm}$ and $30 \mathrm{~mm}$ thickness base plate under various axial loadings. Base-plate connections with HEB 160 column. 

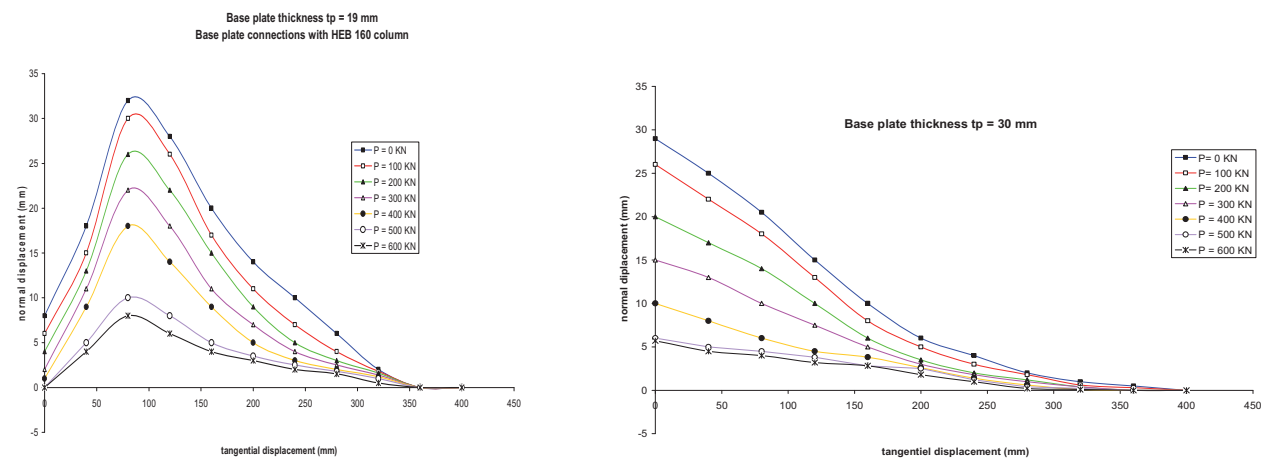

Fig.9. Curves of the normal and tangential displacement of the $19 \mathrm{~mm}$ and $30 \mathrm{~mm}$ thickness base plate.

\section{Conclusions}

1. For the column-base plate connection with only two anchors bolts without compressive load, the conclusions are:

- Rising of the base plate side of traction

- The anchors bolts were lengthened and bent

- The columns did not undergo any deformation; all rotation is occurred on the level of connection.

2. For the same connection with two anchors bolts in the presence of compressive load $(P=[100-400]$ $\mathrm{KN}$ ), the rising of the base plate side of traction is still definitely visible but less important (reduction from 6 to $16 \%$ ). We notice that a contact zone is established under the right end of the base plate. The resting part of the plate starts to separate from concrete foundation, tensioning the left bolt. The deformation of the base plate as well as the plastic strains decrease as axial load increases.

3. For the column-base plate connection with four anchors bolts without compressive load, the conclusions are:

- Rupture of two anchors bolts in traction.

- The base plate was raised considerably before the rupture of the anchors bolts. Rising maxima are $(36 \mathrm{~mm}, 32 \mathrm{~mm}$ and $29 \mathrm{~mm})$ respectively for the base plate thickness $\left(t_{p}=11 \mathrm{~mm}, t_{p}=19 \mathrm{~mm}\right.$ and $\left.t_{p}=30 \mathrm{~mm}\right)$. Comparing the result with the model with base plate thickness $t_{p}=30 \mathrm{~mm}$ to the result with the model with base plate thickness $t_{p}=11 \mathrm{~mm}$, the highest uplift is slightly smaller, as well as the separation length. These results are natural, since the stiffness of the base plate increases for thickness $t_{p}=30 \mathrm{~mm}$, permitting smaller deformability and reducing its final plastic strain.

- Side of compression, there is friction of the base plate over an $80 \mathrm{~mm}$ length counted starting from the end of the base plate.

4. Maintaining for same connections (HEB 160 with four anchors bolts) in presence of compressive load $(\mathrm{P}=[100-600] \mathrm{KN})$, our conclusions are:

- The rising of base plate is less visible than when there is no compressive load.

- The contact area increases along with the axial loading from 0 to $600 \mathrm{KN}$.

- We notice that the bending of the base plate is reduced in comparison with the connection without compressive load. This proves that the increase of the stiffness of the base plate significantly affects its response under applied axial loading and bending moment combination.

- The rising of base plate side of traction is less and less important when the compressive load increases. The reduction of maximum rising is of the order respectively of (6 to $70 \%)$ while passing from compressive load of $\mathrm{P}=100 \mathrm{KN}$ to $\mathrm{P}=600 \mathrm{KN}$.

- Local warping of the wing in compression.

- Traction at the base of column is same side as the wing in compression at the top of column. What shows well that a moment is developed in the connection and the column works in double curve. 
5. For the connections with hollow cross-section, the rising of base plate is even less visible.

6. Increasing the base plate thickness, the stiffness it possesses permits limited deformation which is slightly visible.

\section{References}

[1] Stockwell Jr.FW. Preliminary base plate selection. Engineering Journal, A.I.S.C., Vol 12, $\mathrm{N}^{\circ}$ 3, third quarter, 1975.

[2] Sandhu BS. Steel column base plate design. Engineering Journal, A.I.S.C., Vol. 10, No 4, fourth quarter, 1973.

[3] Bird WR. Rapid selection of column base plate. Engineering Journal, A.I.S.C., Vol 13, N 2, Second Qaurter.

[4] Règles de calcul des constructions en acier et additive 80. 12éme Edition 1988.

[5] Eurocode 3. Design of steel structures, 1.1, General rules for building, Env 1993-1-1, 1992.

[6] Picard A. and Dion, J. Etude expérimentale des assemblages poteau - fondation dans les charpentes d'acier. Department of Civil Engineering, Laval University, Québec, Que. Report 1981, GCT-81-04.

[7] Samson G., Beaulieu D. Etude de la stabilité d'un poteau avec attache semi-rigide à la fondation. Department of Civil Engineering, Laval University, Québec, Que. Report 1982, GCT-83-01.

[8] Pérusse B., Beaulieu D. Etude expérimentale de la rigidité d'un assemblage poteau - fondation de type standard. Department of Civil Engineering, Laval University, Québec, Que. Report 1985, GCT-85-07.

[9] Dewolfe JT. Axially loaded column base plates. Journal Structures. Div ASCE 1978 ;104 : 781-94.

[10] Dewolfe JT, Sansely EF. Columnbase plates with axial loads and moments. Journal Structures Div ASCE $1983 ; 106: 2167-84$.

[11] Thambiratnam DP, Paramasivan P. Base plates under aial loads and moments. Journal Structures Div ASCE $1986 ; 112: 1166-81$.

[12] Cook RA, Klinger RE. Ductile multiple-anchor steel- to-concrete connections. Journal Structures. Div ASCE 118: 1645-1665.

[13] Fling RS. Design of steel bearing plates. Engineering Journal AISC $1970 ; 7$ : 37-40.

[14] Murray TM. Design of lightly loaded steel column base plates. Engineering Journal.AISC 1983; 20 : $92-$ 99 143-152.

[15] Krishnnamurthy N, Graddy DD. Correlation between 2-and 3- dimensional finte element analysis of steel bolted end-plate connections. Compu Struct $1976 ; 6: 381-9$.

[16] Hamizi M, Hannachi, N.E. Evaluation par la méthode des éléments finis du facteur de flexibilité et du degré de fixité des pieds de poteaux les plus couramment utilisés. Annales du Batiment et des travaux publics. Avril juin 2007- $\mathrm{N}^{\circ} 2-3$.

[17] Krishnnamurthy N. A fresh look at bolted steel end-plate behavior and design. Engineering Journal AISC $1978 ; 15: 39-49$.

[18] Kato B, Mcguire W. Analysis of T stub flange to column connection. Journal Structures. Div ASCE 1973 ; $99: 865-88$.

[19] Paker SA, Morris LJ. A limit state design method for tension of bolted column Connections. Structures Enginnering $1977 ; 55: 876-89$.

[20] Kukreti AR, Muray TM. Abolmaali A. Endplate connection moment-rotation relationship. Structures Steel Res $1987 ; 8: 137-57$.

[21] Chen WF, Patel KV. Static behaviour of beam-to-column moment. Journal structures Div ASCE 1981; 197: 1815-38.

[22] Chen WF, Lui EM. Steel beam-to-column moment connections. Part 1 : flange moment connections. S M Arch $1986 ; 11: 257-316$.

[23] Bortmann J, Szabo BA. Nonlinear models for fastened structural connections. Comput Struct 1992; 43 : 909-1023.

[24]Thambiratnam DP,Krishnnamurthy N. Computer analysis of column base plates. Comput Struct 1989; 33 : $839-50$.

[25] Baniotopoulos CC, Karoumbas G, Panagiotopoulos PD. A contribution to the analysis of steel connections by means of quadratic programming techniques. In : proceedings of 1st European Conference on Numerical Methods in Engineering. Amsterdam : Elsevier, 1992. P. 519-525.

[26] Hamizi M, Beaulieu D. Etudes expérimentale et numérique des pontages métalliques. Department of Civil Engineering, Laval University, Québec, Que. Report GCT-87-05.

[27] Champaney, L. Contact unilatéral entre solides élastiques. Notes de cours 'Eléments finis' du DESS

Dynamique des Structures Modernes dans leur Environnement. 